\title{
MIRAGE Syndrome
}

National Cancer Institute

\section{Source}

National Cancer Institute. MIRAGE Syndrome. NCI Thesaurus. Code C147530.

An autosomal dominant condition caused by mutation(s) in the SAMD9 gene, encoding sterile alpha motif domain-containing protein 9A. It is a syndromic condition comprising myelodysplasia, infection, restriction of growth, adrenal hypoplasia, genital abnormalities, and enteropathy. 